\title{
Experimental Research on Citation Tone of Heshun Dialect in Shanxi Province
}

\author{
Ying $\mathrm{Li}^{1,}$, Yonghong $\mathrm{Li}^{2, \mathrm{~b}, *}$ \\ ${ }^{1,2}$ Key Lab of China's National Linguistic Information Technology, School of Northwest Minzu \\ University, Lanzhou 730030, China \\ a1024715445@qq.com, b*lyhweiwei@126.com \\ *corresponding author
}

Keywords: Heshun dialect; citation tone; fundamental frequency; fifth degree

Abstract: Based on the recording data of fieldwork, this paper employs the method of experimental phonetics to extract the pronunciation time and fundamental frequency, then analyzes the fundamental frequency pattern and vocal range, and summarizes the specific types of tone and the tone value of Heshun dialect. Ping is divided into Yinping and Yangping, the voiced Shang belongs to $\mathrm{Qu}$, and $\mathrm{Ru}$ is still reserved in Heshun dialect, and finally, finds that Heshun dialect has 5 tones: Yinping (52), Yangping (32), Shang(55), $\mathrm{Qu}(31), \mathrm{Ru}(32)$.

\section{Introduction}

Heshun county is located in the east of Shanxi Province and the west of the Taihang Mountain. The unique geographical environment makes the dialect of Heshun appear unique. According to the Chinese Language Atlas (1987), Study of Modern Jin language and Division of Jin language, Heshun dialect belongs to Dabao region of Jin language. There is a certain difference in pronunciation among towns and villages in Heshun region. This article focuses on the pronunciation of town district.

At present, there are a few of records and studies on the pronunciation of Heshun dialect. The main references are Heshun Dialect (1990) and Shanxi Dialects Research Report (1993), which recorded and described the phonetic system of Heshun dialect. The Heshun dialect pointed out that there are 24 initials, 37 finals, and 5 tones. The value of five tones are respectively Yinping(31), Yangping (22) ,Shang(35), Qu (44) , $\mathrm{Ru}(21)$. We will use the method of experimental phonetics to verify it.

In the surveys of Chinese dialects, theoretical linguists usually use the traditional methods to listen and note the sound. There may be some uncertainty in the process. In contrast, we can make full use of advanced softwares and instruments to research. Analyzing these acoustic features of sound can make up for the deficiency of listening. Therefore, this study will collect sound signals in the form of data, and combine with experimental methods to determine the specific types of tone and the tone value of Heshun dialect. 


\section{Experimental Description}

\subsection{Pronunciation partner}

This study selected a 30-year-old female speaker who is a native of Heshun. She had a certain education and was familiar with Heshun dialect. Above all, she pronounced clearly.

\subsection{Experimental equipment}

We selected a professional recording studio to record. The recording software was Adobe Audition 3.0, the sampling rate was 44100s, with 16-bit resolution. The analysis softwares included Pratt5.0 and Matlab.Besides, we also used the sound console, external sound cards and microphone.

\subsection{Pronunciation list}

The pronunciation list was based on the Chinese Language Resources Survey Handbook and the Dialect Word Survey Table, combined with the Various Rhymes. On the one hand, according to the recorded of Heshun Dialect, Heshun dialect still reserved $\mathrm{Ru}$, and Ping divided into Yinping and Yangping. Therefore, this study selected more words about Ping and $\mathrm{Ru}$. On the other hand, according to the classification of ancient tones and sounds, each tone can be divided into voiceless, asperational voiceless, secondary voiced and voiced. So, we selected 116 typical examples, as shown in Table 1.

Table 1 Pronunciation List

\begin{tabular}{|c|c|c|c|c|}
\hline $\begin{array}{l}\text { Ancien tone } \\
\text { Ancient sound }\end{array}$ & Ping & Shang & $\mathrm{Qu}$ & $\mathrm{Ru}$ \\
\hline Voiceless & $\begin{array}{l}\text { 东该灯风波 } \\
\text { 衣贞书加师 }\end{array}$ & $\begin{array}{l}\text { 懂 古 } \\
\text { 鬼 九 }\end{array}$ & 四布帝 戏 记 & $\begin{array}{l}\text { 急七一吸湿 } \\
\text { 织窄笔曲竹 }\end{array}$ \\
\hline $\begin{array}{c}\text { Asperational } \\
\text { voiceless }\end{array}$ & $\begin{array}{l}\text { 通开天春坡 } \\
\text { 青窗方听粗 }\end{array}$ & $\begin{array}{l}\text { 统 苦 } \\
\text { 讨草 }\end{array}$ & 去怕替次破 & $\begin{array}{l}\text { 切拍铁说擦 } \\
\text { 发吃掐泼缺 }\end{array}$ \\
\hline $\begin{array}{l}\text { Secondary } \\
\text { voiced }\end{array}$ & $\begin{array}{l}\text { 门龙牛油刘 } \\
\text { 姨赢驴眉棉 }\end{array}$ & $\begin{array}{l}\text { 买 老 } \\
\text { 五 有 }\end{array}$ & 卖厉艺路雾 & $\begin{array}{l}\text { 入六热袜月 } \\
\text { 捏密木绿摸 }\end{array}$ \\
\hline Voiced & $\begin{array}{l}\text { 铜皮糖红婆 } \\
\text { 晴床防庭迟 }\end{array}$ & $\begin{array}{l}\text { 动 罪 } \\
\text { 近 后 }\end{array}$ & 事住大地字 & $\begin{array}{l}\text { 白合读杂十 } \\
\text { 绝笛择达舌 }\end{array}$ \\
\hline
\end{tabular}

\subsection{Data extraction and analysis}

First of all, we used Praat5.0 software to collect data, which included the pronunciation time and fundamental frequency. Next, normalized the fundamental frequency by running a normalized script program in Matlab.Each instance had a corresponding value of 30 fundamental points. Then took the average value of the selected frequency points of each tone. Finally, we converted the fundamental frequency value to the five-degree value and made a corresponding T-value figure. When the fundamental frequency was normalized, we used the $\mathrm{T}$ algorithm and the formula was:

$$
\mathrm{T}=[(\lg 0-\operatorname{lgmin}) /(\lg \max -\lg \min )] * 5
$$

Among them, F0 represented the fundamental frequency value. Min refered to the lower limit of the fundamental frequency. Max was the upper limit of the modulation range. T represented the final normalized result. At the same time, we should pay attention to the vocal range. Used the statistical data of fundamental frequency to establish a standardized vocal range pattern. The main 
parameters included the upper limit of the range( $\mathrm{RH})$, the lower limit of range(RI), and the width of field(R).

\section{Experimental Results and Discussion}

\subsection{Pronunciation time}

In the process of researching Heshun dialect, we can extract the pronunciation time of the speaker. Analyze the average pronunciation time of each tone and draw a figure, as shown in figure 1.

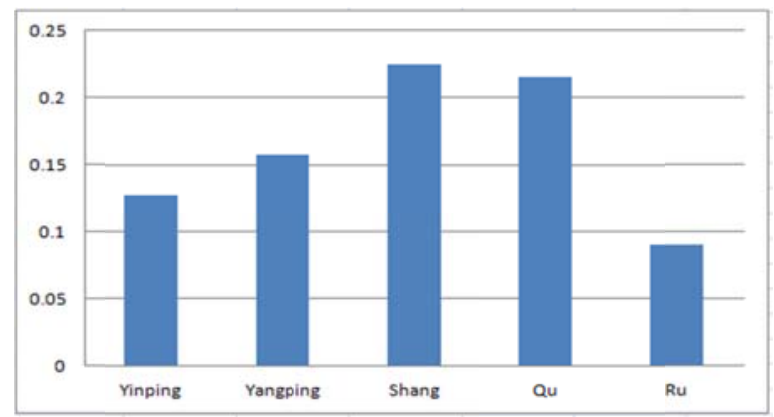

Fig. 1 The average of pronunciation time

The pronunciation time of Yinping is $0.128 \mathrm{~s}$, Yangping is $0.158 \mathrm{~s}$, Shang is $0.225 \mathrm{~s}$, Qu is $0.215 \mathrm{~s}$, and $\mathrm{Ru}$ is $0.09 \mathrm{~s}$. Therefore, we can find that Yinping and Yangping have lower pronunciation time than $\mathrm{Qu}$. The shortest pronunciation time of $\mathrm{Ru}$ is enough to show that Heshun dialect has well preserved the tone.

\subsection{Fundamental frequency and vocal range}

After extracting the fundamental frequency of all citation tone samples, we can get the average of fundamental frequency value. The parameters include initial mean value, middle mean value, final mean value, maximum value, and minimum value, as shown in Table 2.

Table 2 Heshun fundamental frequency parameters $(\mathrm{Hz})$

\begin{tabular}{|c|l|c|c|c|c|c|}
\hline \multicolumn{2}{|c|}{ Tones } & $\begin{array}{c}\text { Initial } \\
\text { mean value }\end{array}$ & $\begin{array}{c}\text { Middle } \\
\text { mean value }\end{array}$ & $\begin{array}{c}\text { Final } \\
\text { mean value }\end{array}$ & $\begin{array}{c}\text { Maximum } \\
\text { value }\end{array}$ & $\begin{array}{c}\text { Minimum } \\
\text { value }\end{array}$ \\
\hline \multirow{4}{*}{ Ping } & Voiceless & 276.1 & 246.7 & 198.7 & 309.9 & 175.8 \\
\cline { 2 - 7 } & Asperational voiceless & 298.8 & 253.4 & 210.7 & 318.4 & 193.9 \\
\cline { 2 - 7 } & Secondary voiced & 205.6 & 215.2 & 184.1 & 218.6 & 170.7 \\
\cline { 2 - 7 } & Voiced & 243.3 & 204.6 & 181.9 & 256.6 & 145.5 \\
\hline \multirow{4}{*}{ Shang } & Voiceless & 257.5 & 283.7 & 290.4 & 307.2 & 235.0 \\
\cline { 2 - 7 } & Asperational voiceless & 263.6 & 271.4 & 274.4 & 291.5 & 248.4 \\
\cline { 2 - 7 } & Secondary voiced & 254.7 & 271.6 & 278.9 & 312.9 & 236.6 \\
\cline { 2 - 7 } & Voiced & 222.0 & 203.0 & 176.6 & 235.5 & 170.3 \\
\hline \multirow{4}{*}{$\mathrm{Ru}$} & Voiceless & 207.6 & 193.8 & 153.2 & 217.2 & 118.4 \\
\cline { 2 - 7 } & Asperational voiceless & 224.0 & 202.2 & 185.3 & 237.4 & 173.6 \\
\cline { 2 - 7 } & Secondary voiced & 207.7 & 197.2 & 147.5 & 216.2 & 164.6 \\
\cline { 2 - 7 } & Voiced & 201.1 & 192.1 & 159.4 & 213.0 & 131.4 \\
\hline \multirow{4}{*}{$\mathrm{Ru}$} & Voiceless & 226.9 & 207.1 & 191.8 & 241.7 & 182.8 \\
\cline { 2 - 7 } & Asperational voiceless & 228.4 & 207.8 & 191.6 & 250.2 & 187.4 \\
\cline { 2 - 7 } & Secondary voiced & 205.6 & 195.7 & 177.2 & 216.2 & 161.2 \\
\cline { 2 - 7 } & Voiced & 217.3 & 200.1 & 187.7 & 226.6 & 164.9 \\
\hline
\end{tabular}


According to the voicing of the initials, Ping can be divided into Yinping and Yangping. Among them, the voiceless initials belong to Yinping, the voiced initials belong to Yangping, and Heshun dialect is also the same. Yinping and Yangping are falling tones, but Yinping's maximum value, minimum value, and vocal range are significantly higher than Yangping.

The maximum frequency value is $312.9 \mathrm{~Hz}$, the minimum value is $170.3 \mathrm{~Hz}$, and the field width is $142.6 \mathrm{~Hz}$ in Shang. The vocal range is relatively large. Meanwhile, the fundamental frequency parameters of the voiceless, asperational voiceless and secondary voiced of Shang are relatively close, and the change trend is the same, which is a flat tone. However, there is a clear difference between the voiced Shang and the three formers.

The maximum frequency value is $237.4 \mathrm{~Hz}$, the minimum value is $118.4 \mathrm{~Hz}$, and the field width is $119 \mathrm{~Hz}$ in $\mathrm{Qu}$. In Heshun dialect, the voiced Shang and $\mathrm{Qu}$ have similar fundamental frequency parameters and change trend, so the voiced Shang is merged into $\mathrm{Qu}$ as a falling tone.

The maximum frequency value is $250.2 \mathrm{~Hz}$, the minimum value is $161.2 \mathrm{~Hz}$, and the field width is $89 \mathrm{~Hz}$ in $\mathrm{Ru}$. According to the fundamental frequency parameters and change trend of $\mathrm{Ru}$, it is also a falling tone.

In summary, compared with the ancient tones, Heshun dialect indeed has undergone some changes. In Heshun dialect, Ping is divided into Yinping and Yangping, the voiced Shang falls into $\mathrm{Qu}$, and $\mathrm{Ru}$ is reserved. The evolution of ancient and modern tones of Heshun dialect is shown in Figure 2.

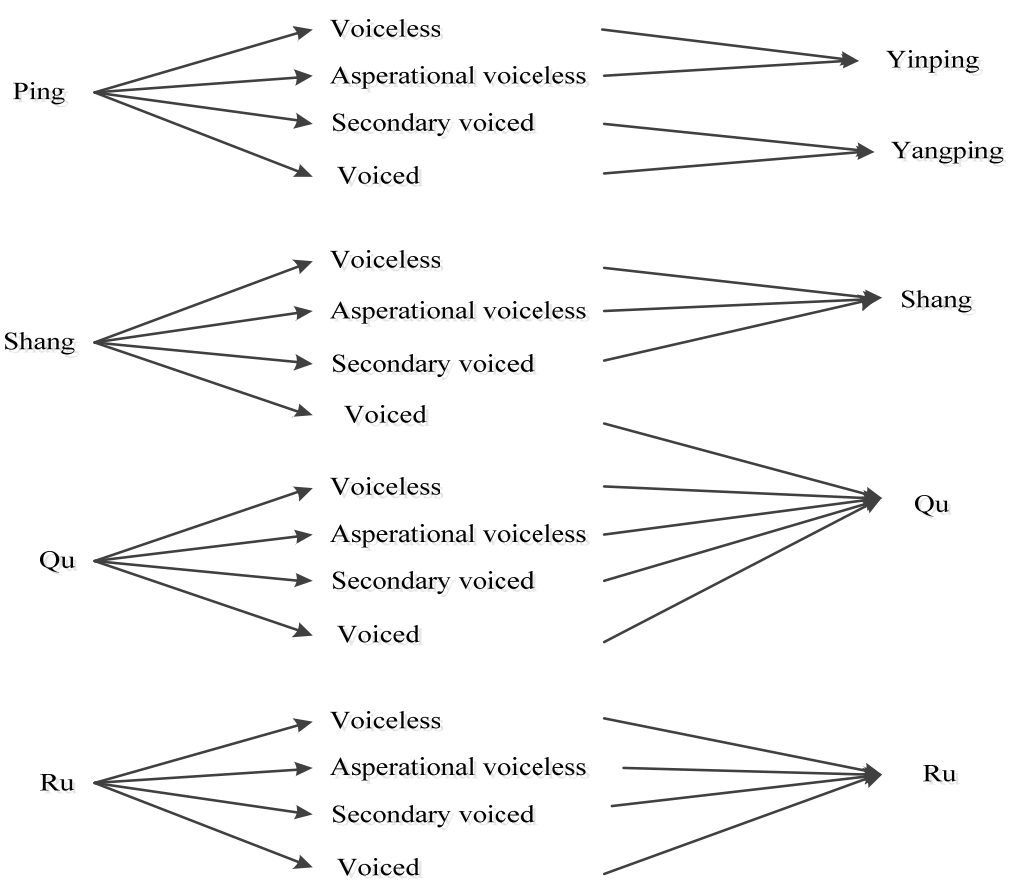

Fig. 2 The tones evolution of Heshun dialect

\subsection{Fifth degree value}

According to the T-value algorithm, we convert the normalized average of the fundamental frequency into traditional fifth-degree value. Finally, we obtain the corresponding five-degree value of each tone and draw the T-value curve. The abscissa is the number of tone points and the ordinate is the fifth degree value. Specifically seen in Figure 3, Figure 4, Figure 5, and Figure 6. 


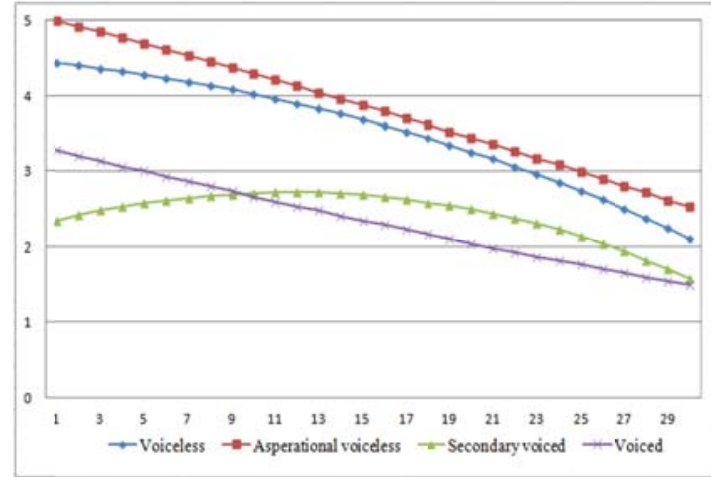

Fig. 3 T-value curve of Ping

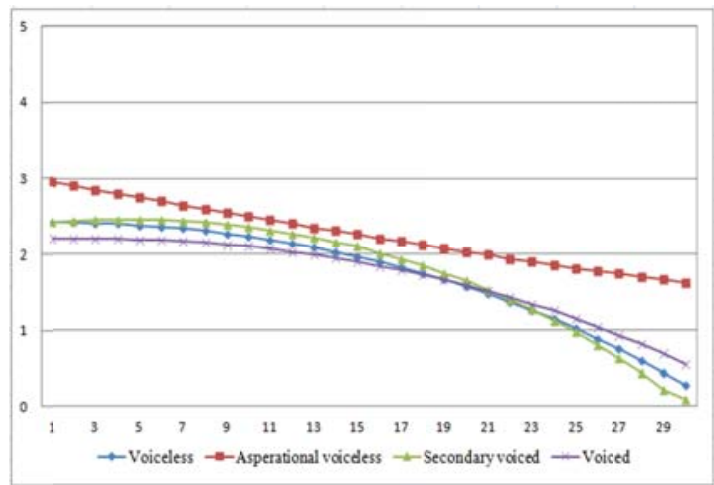

Fig. 5 T-value curve of Qu

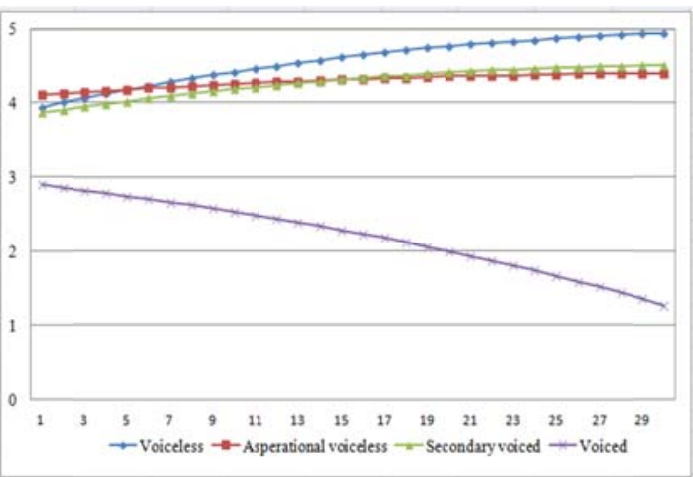

Fig. 4 T-value curve of Shang

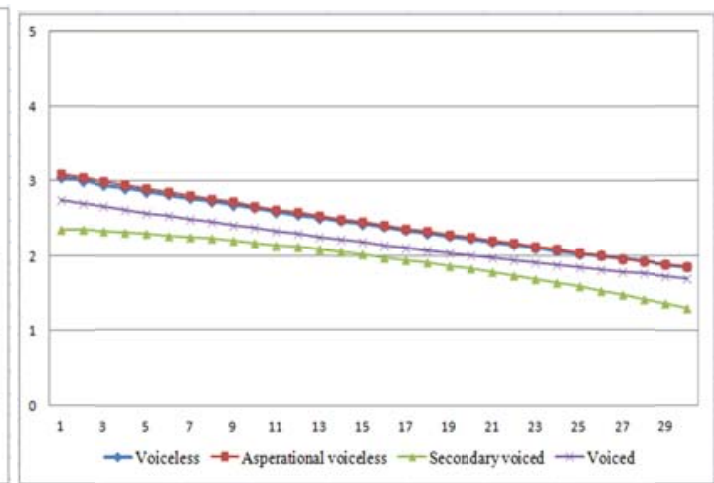

Fig. $6 \mathrm{~T}$-value curve of $\mathrm{Ru}$

Through the above four figures, we can clearly see the specific types of tone and tone value. Among them, the specific type of tone and tone value of Yangping are close to Qu, but there are some subtle differences between them. The native speaker can distinguish the difference relying on perception. Therefore, in order to understand and compare the various types of tone more intuitively, we draw a T-value curve of Heshun dialect, as shown in Figure 7.

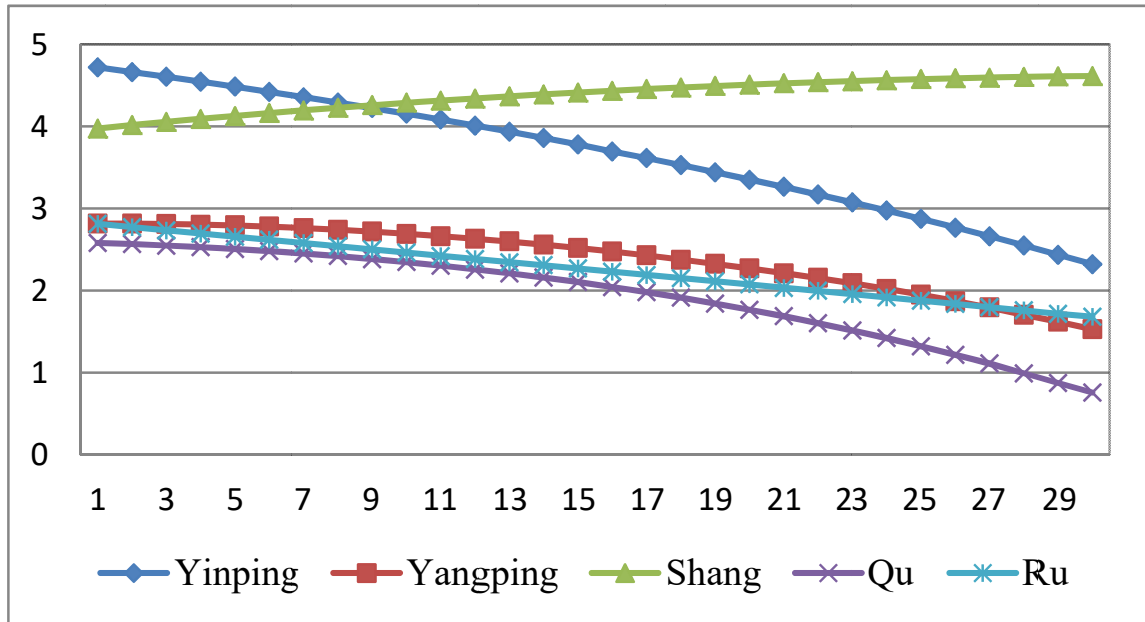

Fig. 7 T-value curve of Heshun dialect

As we can see from figure 7, the specific tones value of Heshun dialect are Yinping (52), Yangping(32), Shang(55), $\mathrm{Qu}(31)$, and $\mathrm{Ru}\left(\Gamma^{2} 32\right)$. The specific tone category, tone types, tone value and tone mark of Heshun dialect have been listed in Table 3. 
Table 3 The citation tones of Heshun dialect

\begin{tabular}{|c|c|c|c|c|c|}
\hline Tone categories & Yinping & Yangping & Shang & $\mathrm{Qu}$ & $\mathrm{Ru}$ \\
\hline Tone types & High falling & Low falling & High level & Low falling & Low falling \\
\hline Tone value & 52 & 32 & 55 & 31 & $\nwarrow 32$ \\
\hline Tone mark & $\checkmark$ & $\checkmark$ & $\bullet$ & $<$ & $\vee$ \\
\hline
\end{tabular}

\section{Conclusion}

This research mainly uses the method of experimental phonetics to study the acoustic features of Heshun dialect. By analyzing the pronunciation time, the fundamental frequency parameters and vocal range, we can describe the specific types of tone and tone value of Heshun dialect in many aspects. The results of this study show that Heshun dialect has five tones.Yinping is a high falling tone, its value is 52.Yangping is a low falling tone, its value is 32. Shang is a high level tone, its value is 55 . Qu is a low falling tone, its value is 31 . Ru is also a falling tone, its value is $\sqsubset 32$. In general, the results of this study are different from these recorded in Heshun Dialect, but I hope that these will be helpful in the research of Heshun dialect and Jin language.

\section{Acknowledgement}

This work was financially supported by the Central University Innovation Project Multi-mode Phonetic Research (31920160002).

\section{References}

[1] Wen Duanzheng and Hou Jingyi. The Survey Report for Shanxi dialect[M]. Taiyuan: Shanxi University Press, 1993.

[2] Hou Jingyi. Study of modern Jin dialect [M]. Commercial Press, 1999.

[3] Han Peiling. Research on the Phonological Rhythm of Shanxi Dialect[M]. Commercial Press, 2012.

[4] Kong Jiangping. Basic course of experimental phonetics[M]. Beijing: Peking University Press, 2013.

[5] Shen Ming. The Division of the Jin Language (Manuscript)[J]. Dialect, 2006(04):343-356.

[6] Wang Linhui.The Types of Tones in the Shanxi Dialect (Manuscript)[J]. Language Studies,2003(02):53-57.

[7] Wang Hongjie, Li Yonghong. Experimental research on citation tone of Guangling dialect[J]. Journal of Northwest University Nationalities (Natural Science). 2016, 38(1).

[8] Li Xi. Research on the Tones of Shanxi Dialect[D]. Shaanxi Normal University, 2014.

[9] Qiao Quansheng.The flat tone of Jin dialect and its historical evolution[J]. Chinese Language and Literature,2007(04):302-305.

[10] Liu Yuanyuan. The study of dialectal phonetics in Shanxi Heshun dialect [D]. Shanxi University, 2014.

[11] Xiang Ning, Shi Feng. Acoustic Experiment and Statistical Analysis of Single Words in Changsha Language [J]. Linguistic Studies. 2007, 27(2).

[12] LI Bing, Liu Yanni. Experimental phonetics report of citation tone and tone modification of Changsha dialect [J]. Journal of Hunan University (Social Science Edition), 2006(04):107-112. 